\title{
Primary pulmonary vein stenosis: The impact of sutureless repair on survival
}

\author{
Nicola Viola, MD, ${ }^{\mathrm{a}}$ Abdullah A. Alghamdi, MD, ${ }^{\mathrm{b}}$ Donald G. Perrin, PhD, PA, ${ }^{\mathrm{c}}$ Gregory J. Wilson, MD, ${ }^{\mathrm{c}}$ \\ John G. Coles, MD, and Christopher A. Caldarone, $\mathrm{MD}^{\mathrm{b}}$
}

Background: Primary pulmonary vein stenosis is often associated with relentless restenosis and early death. During the last 2 decades, we have developed a sutureless repair to improve prognosis.

\begin{abstract}
Methods: Hospital records for patients undergoing repair of primary pulmonary vein stenosis from 1989 to 2008 were reviewed. Pulmonary vein stenosis was quantified with a pulmonary vein stenosis score. Survival was determined by Kaplan-Meier analysis.

Results: Twenty-three patients underwent surgical repair. Mean ages at diagnosis and index repair were $23.3 \pm$ 45.6 and $24.1 \pm 40.9$ months, respectively. Systemic or suprasystemic pulmonary artery pressures were present in 13 of 18 patients (72\%). Seven (31\%) had single-ventricle circulation. A sutureless technique was used in 19 of 23 cases $(83 \%)$. Other types of repair were used in 4 of $23(17 \%)$. There were 11 recorded deaths $(47 \%)$. Survivals were $64 \%, 47 \%$, and $31 \%$ at 1,5 , and 10 years, respectively. Five patients $(22 \%)$ required 1 reintervention. Surgical repair significantly reduced the total pulmonary vein stenosis score $(5.6 \pm 2.10$ before repair, $2.6 \pm 2.72$ after repair, $P=.0057)$. The preoperative pulmonary vein stenosis score was the only independent predictor of mortality (hazard ratio, 1.732; $P<.01$ ). A preoperative pulmonary vein stenosis score of greater than 4 was a poor prognostic indicator (area under the curve, 0.83 ).
\end{abstract}

Conclusions: Mortality and restenosis rates remained high despite the adoption of a sutureless technique. A preoperative pulmonary vein stenosis score of greater than 4 was a strong predictor of poor prognosis. (J Thorac Cardiovasc Surg 2011;142:344-50)

Pulmonary vein stenosis (PVS) with normally related pulmonary veins is a rare anomaly, and its presentation can vary in severity between a mild discrete stenosis at the venoatrial junction to long narrow stenotic segments of the pulmonary veins to vein atresia. The involvement of 1 or more veins can produce severe arterial pulmonary hypertension and right ventricular failure, which often leads to death despite repair. ${ }^{1}$ Traditional surgical pulmonary venoplasties and percutaneous interventions have yielded disappointing results because of high incidences of restenosis and persistent pulmonary hypertension. ${ }^{2-5}$

So-called sutureless techniques have been previously described for repair of recurrent stenosis after repair of total anomalous pulmonary venous connection ${ }^{4-6}$ but have not yet been evaluated for repair of primary PVS. In light of

From the Department of Thoracic and Cardiovascular Surgery, ${ }^{\text {a }}$ Southampton University Hospital, Southampton, United Kingdom; and the Division of Cardiovascular Surgery, ${ }^{\mathrm{b}}$ Department of Surgery, and the Division of Pathology, ${ }^{\mathrm{c}}$ Department of Pathology and Laboratory Medicine, the Hospital for Sick Children, Toronto, Ontario, Canada.

Disclosures: Authors have nothing to disclose with regard to commercial support.

Read at the American Heart Association Scientific Sessions, Orlando, Fla, 2009.

Received for publication May 22, 2010; revisions received Sept 21, 2010; accepted for publication Dec 6, 2010; available ahead of print Jan 31, 2011.

Address for reprints: Nicola Viola, MD, Southampton University Hospital,7 Tremona Rd, North Wing, D Level, Southampton, Hampshire, SO16 6YD, UK (E-mail: nicola.viola@suht.swest.nhs.uk).

0022-5223/\$36.00

Copyright (C) 2011 by The American Association for Thoracic Surgery doi:10.1016/j.jtcvs.2010.12.004 the poor prognosis for patients with primary PVS, we sought to review our surgical experience in the treatment of primary PVS. Our objectives were to evaluate the use of the PVS score as previously described ${ }^{4}$ as an estimate of the severity of disease, to evaluate the impact of the sutureless technique on surgical outcomes, and to identify risk factors for surgical success and failure in the treatment of primary PVS.

\section{MATERIALS AND METHODS Population}

After approval from the research ethics board at the Hospital for Sick Children, we searched our Cardiovascular Surgery Database between September 1989 and October 2008 and identified 23 patients with primary PVS. Patients with previous pulmonary vein surgery (eg, repair of anomalous pulmonary venous drainage) were excluded. Hospital records were reviewed, and follow-up data were obtained by contacting the treating cardiologists. Patient characteristics are shown in Table 1.

There were 9 premature neonates $(39.1 \%)$, with a median gestational age of $32 \pm 4$ weeks (range, 25-36 weeks). The mean age at diagnosis was 23.3 \pm 45.6 months (range, 0.1-183.3 months), and the mean age at first surgical repair was $24.1 \pm 40.9$ months (range, 1.1-162.4 months), with a mean weight of $10.05 \pm 11.6 \mathrm{~kg}$ (range, $2.3-49.5 \mathrm{~kg}$ ). Thirteen patients had systemic or suprasystemic pulmonary pressures at the time of diagnosis.

All patients had associated cardiac anomalies. Seven patients $(30.4 \%)$ had a univentricular circulation. One patient had scimitar syndrome in association with primary stenosis of left-side pulmonary veins. A second patient had cor triatriatum in association with bilateral long stenosis of left pulmonary veins. A third patient had a supramitral membrane. Six of the 7 patients with univentricular circulation had some form of palliation at the time of the index operation. Surgical procedures performed before 


\section{Abbreviation and Acronym}

$\mathrm{PVS}=$ pulmonary vein stenosis pulmonary vein surgery included 2 ventricular septal defect closures and 2 patent ductus arteriosus ligations. One patient had undergone emergency right ventricular repair for acute perforation caused by a diagnostic catheterization.

\section{PVS Score}

PVS score has been previously proposed as a subjective measure of disease burden. ${ }^{5}$ To calculate the score, each pulmonary vein was assessed independently, and the degree of stenosis was evaluated on the basis of 2-dimensional description and Doppler interrogation. The diameter of the veins (expressed in millimeters) was measured on 2-dimensional imaging. Flow velocities were recorded at the venoatrial junction to provide a pressure gradient. Diffusely narrow veins were also identified. Each vein was assigned a number between 0 and 3 . A score of 0 indicated the absence of stenosis or hypoplasia and unobstructed, biphasic blood flow. A score of 1 indicated mild to moderate stenosis, with a minimum pulmonary vein diameter of about 3 to $4 \mathrm{~mm}$ and a pressure gradient measured at the venoatrial junction of less than $6 \mathrm{~mm} \mathrm{Hg}$. A score of 2 indicated severe stenosis with a pinpoint ostium and a pressure gradient greater than $7 \mathrm{~mm}$ $\mathrm{Hg}$. A score of 3 indicated occlusion or atresia of the pulmonary vein. Scores were calculated after every echocardiographic examination performed. PVS scores were validated by 1 observer (A.A.A.) who independently reviewed a sample of 113 vein images. Their observations were weighted against the echocardiographic reports completed by experienced cardiologists at our institution. Complete concordance between observers was found in $97 \%$ of the samples. Scores obtained for each vein were summed to obtain the total PVS score.

Operative reports were reviewed and consistently mentioned the operating surgeon's observations stating the diameter of the vein at the venoatrial junction or the presence of diffuse vein hypoplasia. Surgical and postmortem histologic sampling, venoangiography, magnetic resonance angiography, and computed tomographic scan were inconsistently performed and therefore not used as primary sources of scoring data but rather used to strengthen the echocardiographic analysis (Figure 1).

\section{Statistical Analysis}

A statistical software package (SAS version 9.1; SAS Institute, Inc, Cary, NC) was used for all statistical analyses. Categoric data were summarized as frequencies and percentages, and continuous variables were summarized as mean, medians, and SD. Categoric variables were compared with the $\chi^{2}$ test, and continuous variables were compared with the student $t$ test. Kaplan-Meier statistics were used to compare time to death in different subgroups. Log-rank test with a significance level less than .05 was used to compare survival curves. Stepwise proportional hazard modeling was used to identify possible independent predictors of mortality. Analysis of variance was used to compare PVS scores before and after the repair. Predictive accuracy for the obtained PVS score value was assessed by calculating the area under the receiver operating characteristics curve, and model calibrations and fit were assessed with Hosmer-Lemeshow goodness-of-fit statistics. Longitudinal data analyses of all echocardiographic data were performed to show the averaged trend over time of PVS score.

\section{RESULTS}

Nineteen of 23 patients $(83 \%)$ underwent repair with a sutureless technique. Among these 19 patients, 12
$(52.1 \%)$ underwent repairs on the left side, $6(26 \%)$ underwent bilateral repairs, and $1(4.3 \%)$ underwent repair of the veins on the right side only. Of the remaining 4 patients, $3(13 \%)$ underwent patch venoplasty and $1(4.3 \%)$ underwent bilateral stent insertion.

Operative data are shown in Table 2. Deep hypothermic circulatory arrest was used in 6 cases, with a mean duration of $26.5 \pm 16.5$ minutes. Eleven patients $(47.8 \%)$ underwent additional procedures. The mean hospital stay for the entire cohort was $52.95 \pm 87.85$ days (range, 2-378 days).

Overall survivals for the whole cohort were $64 \%$ at 1 year, $47 \%$ at 5 years, and $31 \%$ at 10 years (Figure 2). The mean survival was $5.5 \pm 1.02$ years (range 1 day-9.7 years). Most deaths occurred during the index hospitalization. The mean interval to last follow-up was $40.2 \pm 42.2$ months (range, 0.1-156) months.

Among the 11 patients who died, 6 (55\%) had no relief of PVS and pulmonary hypertension at first repair, $4(36 \%)$ had initial relief of the stenosis but then had restenosis that was clinically significant, and $1(9 \%)$ died of irreversible pulmonary hypertension and lung infection despite significant intraoperative reduction of the PVS score. Among those who underwent repair without the sutureless technique, only 1 was alive at last follow-up.

Three patients (27\%) underwent at least 1 reintervention. One of these patients had undergone repair without the sutureless technique. The other 2 patients underwent reoperation twice; both underwent extension of the previous sutureless repairs and subsequent percutaneous stenting. All reinterventions were unsuccessful in relieving the stenosis.

Among the 12 patients who survived to most recent follow-up, 6 patients $(50 \%)$ had significant relief of the initial stenosis that persisted to the most recent echocardiographic examination. In contrast, in 3 patients $(25 \%)$ there was a progressive increase in PVS score. Finally, in 3 patients $(25 \%)$ surgical repair failed to achieve a significant reduction in the PVS score. These patients were described in the operative report as having diffusely narrow pulmonary veins, with internal diameter less than $3 \mathrm{~mm}$.

As noted previously, 2 patients underwent reoperative sutureless repair. In both cases, the surgical anastomosis was brought beyond the pericardium into the lung hilum to reach the intraparenchymal portion of the veins, with a successful result in 1 case and persistent mild stenosis at follow-up in the other.

Although the clinical and functional statuses of survivors were not investigated in this study, no patients at the time of review had undergone lung transplant.

\section{Statistical Analysis}

The following variables were used to predict mortality by stepwise proportional hazard analysis: sex, prematurity, weight at the time of repair, preoperative PVS score 
TABLE 1. Patient characteristics

\begin{tabular}{|c|c|c|c|c|c|c|c|c|}
\hline Subject & Sex & $\begin{array}{c}\text { Premature } \\
\text { (gestational wk) }\end{array}$ & $\begin{array}{c}\text { Age at repair } \\
(\mathrm{mo})\end{array}$ & $\begin{array}{c}\text { Weight } \\
\text { (kg) }\end{array}$ & $\begin{array}{l}\text { Pulmonary } \\
\text { pressure }\end{array}$ & Associated cardiac defects & $\begin{array}{c}\text { Previous } \\
\text { operations }\end{array}$ & $\begin{array}{l}\text { Status at } \\
\text { follow-up }\end{array}$ \\
\hline 1 & $\mathrm{~F}$ & No & 9.4 & 5.3 & - & VSD, PDA & None & Dead \\
\hline 2 & $\mathrm{~F}$ & No & 10.7 & 6.93 & Systemic & ASD & None & Dead \\
\hline 3 & M & No & 17.4 & 10.5 & Subsystemic & HLHS & BCPS & Alive \\
\hline 4 & M & No & 50.4 & 16.3 & - & TGA, tricuspid atresia & Norwood & Alive \\
\hline 5 & $\mathrm{~F}$ & Yes (25) & 6.1 & 5.5 & Suprasystemic & PFO, PDA & None & Alive \\
\hline 6 & M & No & 131.8 & 49.5 & - & DORV, mitral atresia & BCPS & Alive \\
\hline 7 & M & No & 34.8 & 14 & Subsystemic & $\begin{array}{l}\text { TGA, coarctation, tricuspid } \\
\text { atresia }\end{array}$ & BCPS & Alive \\
\hline 8 & M & No & 7.3 & 7.1 & Subsystemic & ASD, VSD, PDA & None & Dead \\
\hline 9 & M & Yes (28) & 10.2 & 6.77 & - & PFO, BAV & None & Alive \\
\hline 10 & M & Yes (26) & 31.4 & 10 & Subsystemic & PFO, PDA & None & Alive \\
\hline 11 & $\mathrm{~F}$ & Yes (32) & 2.1 & 3.1 & Suprasystemic & ASD & None & Dead \\
\hline 12 & M & Yes (32) & 4.3 & 4.5 & Suprasystemic & ASD, VSD & PDA ligation & Dead \\
\hline 13 & M & No & 10.5 & 7.28 & Suprasystemic & ASD, scimitar syndrome & None & Alive \\
\hline 14 & $\mathrm{~F}$ & Yes (27) & 9 & 6.45 & Subsystemic & ASD & None & Alive \\
\hline 15 & M & No & 19.8 & 9.5 & - & HLHS & BCPS & Alive \\
\hline 16 & $\mathrm{~F}$ & No & 1.7 & 4.4 & Systemic & ASD & None & Dead \\
\hline 17 & M & Yes (34) & 6.2 & 2.3 & Suprasystemic & ASD, PDA & None & Dead \\
\hline 18 & $\mathrm{~F}$ & Yes (34) & 16.7 & 5.5 & Suprasystemic & PFO, VSD, ASD & VSD closure & Dead \\
\hline 19 & M & Yes (36) & 2.8 & 2.8 & Suprasystemic & ASD, PDA & None & Dead \\
\hline 20 & M & No & 1.1 & 3.8 & Suprasystemic & PFO, TR, PDA, & RVP & Alive \\
\hline 21 & $\mathrm{~F}$ & No & 10 & 5.5 & Systemic & VSD, cor triatriatum & VSD closure & Alive \\
\hline 22 & $\mathrm{~F}$ & No & 8.1 & 4.04 & Systemic & $\begin{array}{l}\text { VSD, PA, cor triatriatum, } \\
\text { Ebstein anomaly }\end{array}$ & PDA closure & Dead \\
\hline 23 & M & No & 162.4 & 40.2 & Subsystemic & VSD, TGA, PS, mitral atresia & BCPS & Dead \\
\hline
\end{tabular}

$V S D$, Ventricular septal defect; $P D A$, patent ductus arteriosus; $A S D$, atrial septal defect; $H L H S$, hypoplastic left heart syndrome; $B C P S$, bidirectional cavopulmonary shunt; $T G A$, transposition of the great arteries; $P F O$, patent foramen ovale; $D O R V$, double-outlet right ventricle; $B A V$, bicuspid aortic valve; $T R$, tricuspid regurgitation; $R V P$, right ventriculoplasty; $P A$, pulmonary atresia; $P S$, pulmonary stenosis.

\begin{tabular}{|l|l|l|l|l|}
\hline Score & $\begin{array}{l}\text { Echo 2D } \\
\text { Stenosis }\end{array}$ & $\begin{array}{l}\text { Doppler gradient } \\
\text { (Mean- } \mathrm{mmHg} \text { ) }\end{array}$ & $\begin{array}{l}\text { Operative Findings } \\
\text { (Macroscopic) }\end{array}$ & $\begin{array}{l}\text { Pathology } \\
\text { (Microscopic) }\end{array}$ \\
\hline 0 & None & $<2$ & $\begin{array}{l}\text { Normal } \\
\text { Appearance }\end{array}$ & \\
\hline 1 & Mild to Mod & $<5-6$ & $3-4 \mathrm{~mm}$ & \\
\hline 2 & Severe & $>7$ & $<2 \mathrm{~mm}$ & \\
\hline 3 & Occlusion & None & No Lumen & \\
\hline
\end{tabular}

FIGURE 1. Summary of pulmonary vein stenosis score criteria. Diagnosis of pulmonary vein stenosis and consequent scoring were based primarily on echocardiographic (Echo) observations. Preoperative 2-dimensional (2D) and Doppler data correlated with intraoperative macroscopic findings reported by surgeon at time of repair. Postmortem specimens obtained in 5 patients (right column) showed normal venous anatomy in veins previously scored as normal (score 0), mild degree of intimal hyperplasia in veins scored as mild to moderately occluded (score 1), near occlusion of vein with severe degree of hyperplasia in veins scored as severe (score 2), and complete occlusion in veins previously scored 3. 
TABLE 2. Type of repair, associated procedures, and operative data

\begin{tabular}{lc}
\multicolumn{1}{c}{ Variable } & Value \\
\hline Type of repair (no.) & \\
Left-side sutureless repair & $12(52.1 \%)$ \\
Bilateral sutureless repair & $6(26 \%)$ \\
Venoplasty & $3(13 \%)$ \\
Right-side sutureless repair & $1(4.3 \%)$ \\
Bilateral stent & $1(4.3 \%)$ \\
Total & $23(100 \%)$ \\
Associated procedures (no.) & \\
Atrial septal defect closure & $4(17.3 \%)$ \\
Ventricular septal defect closure & $3(13 \%)$ \\
Pulmonary arterial plasty & $2(8.6 \%)$ \\
Ventricular septal defect closure, atrial septectomy & $1(4.3 \%)$ \\
Right ventricular outflow tract plasty & $1(4.3 \%)$ \\
Total & $11(47.8 \%)$ \\
Operative data (median \pm SD) & \\
Cardiopulmonary bypass time (min) & $107.5 \pm 30.6$ \\
Crossclamp time (min) & $63 \pm 26.6$ \\
Deep hypothermic circulatory arrest time (min) & $26.5 \pm 16.5$ \\
Hospital stay (d) & $52.95 \pm 87.85$ \\
\hline
\end{tabular}

(as an indicator of severity of the disease), univentricular circulation, type of primary surgical repair, associated surgical procedures, and use of deep hypothermic circulatory arrest. Only the preoperative PVS score was found to be a significant independent predictor of mortality, with a hazard ratio of $1.732(P<.01)$.

\section{PVS Score Analysis}

The preoperative PVS scores for the entire cohort were $5.6 \pm 2.1$ before repair and $2.6 \pm 2.7$ immediately after repair $(P=.0057)$, suggesting that the surgical procedures achieved the immediate surgical objective in most cases. The mean scores recorded at 1 month $(2.8 \pm 3.2), 3$ months $(3.1 \pm 3.0)$, and 6 months $(3.6 \pm 3.4)$, however, although lower than the preoperative scores, seem to indicate a time-related progressive increase in the severity of PVS, culminating at 6 months when most deaths occurred.

The low scores recorded at 12 months $(2.9 \pm 3.5)$ and at last follow-up $(2.1 \pm 2.5)$ may indicate overall lower preoperative scores before and after surgery among the selected group of patients who survived to follow-up (Figure 3).

Scores were then stratified by survival at 12 months to assess the efficacy of surgery for patients with different preoperative scores. Preoperative scores were significantly higher in the early death group than in the group of those who survived to follow-up $(7 \pm 1.92$ vs $4.4 \pm 1.51$, $P=.0015)$, indicating that nonsurvivors had greater preoperative severity of PVS. Surgery was associated with trend toward reduced differences in the perioperative scores when comparing the groups $(3.5 \pm 3.5$ vs $1.6 \pm 2.1, P=.1036)$. At 1 month in the postoperative period, however, the PVS scores showed a marked discrepancy (with greater severity in the nonsurvivors). This discrepancy continued up to 12

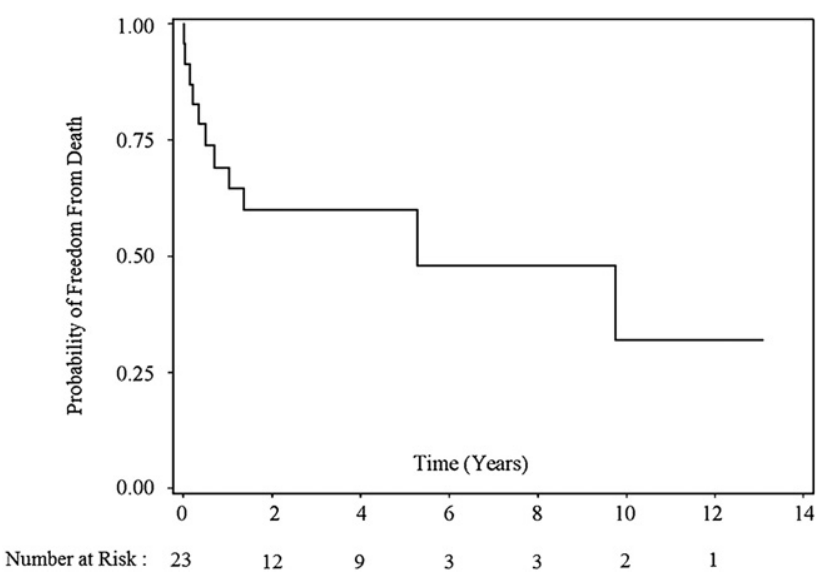

FIGURE 2. Survival distribution for entire cohort after primary repair of pulmonary vein stenosis.

months, suggesting that early restenosis (rather than unsuccessful repair) is among the causes of early death (Table 3 ).

In light of the strong association between preoperative PVS score and overall survival, we evaluated the PVS score with the best predictive value by calculating the area under the receiver operating characteristic curves for all possible preoperative scores (0 to 12$)$. A PVS score of greater than 4 had the best predictive accuracy (area under the curve 0.83 ) for postoperative mortality.

We then performed a longitudinal data analysis that used all PVS scores recorded before, at the time of, and after surgery in an attempt to describe the long-term behavior of the disease (Figure 4). Scores were plotted in trend lines for every patient, and the mean values were calculated and stratified into 2 groups according to preoperative value. Patients with a preoperative score greater than 4 continued to have scores that were consistently high after the repair. In contrast, patients with a preoperative score less than 4 had a temporary respite, with a decline in PVS score followed by a long-term trend toward restenosis at 5 years.

\section{Pathology Specimens}

Pathology specimens were collected from 6 patients, in 2 cases at the time of autopsy. In the remaining 4 cases, specimens were collected and analyzed at the time of primary repair. All specimens were analyzed independently by 2 pathologists (D.G.P., G.J.W.) and were given a score that was based on the same criteria used to assess the veins during repair by the operating surgeon. In patient 1 , macroscopic and microscopic analysis of the autopsy specimen confirmed the PVS score assigned before death. The pathologic findings from the lung biopsy samples also confirmed severe venous pulmonary hypertension with lung hemorrhage, which was diagnosed at the time of death. Pulmonary arteries showed only mild hypertensive changes. Patient 2 was a preterm infant who had undergone operation at the age of 7 months, when pulmonary hypertension and PVS became prominent. 


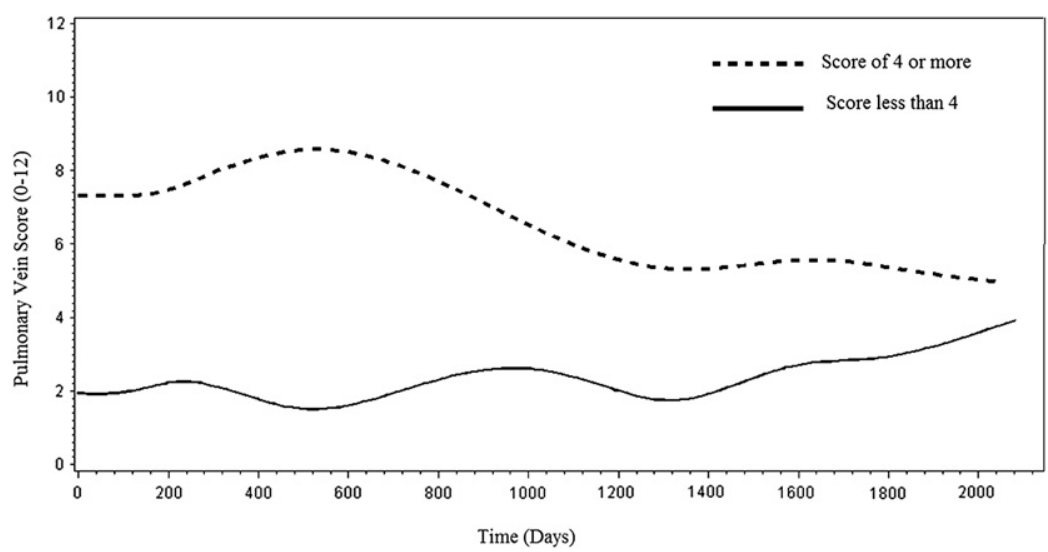

FIGURE 3. Longitudinal data analysis of mean pulmonary vein stenosis scores for patients, stratified by preoperative pulmonary vein stenosis score. Scores were collected from all echocardiographic examinations on record from the time of first diagnosis $(0$ on $\mathrm{x}$-axis) to examination at time of last follow-up.

After a sutureless repair that significantly decreased the degree of stenosis of the individual veins, the patient was discharged to home but died 3 months later of respiratory syncytial virus infection. The left-side veins revealed an unobstructed confluence draining into the left atrium. Mild hypertensive changes on both venous and arterial sides were also noted. In the remaining 6 patients, various degrees of hypertensive changes and PVS were demonstrated, and the pulmonary vein specimens showed degrees of stenosis that were consistent with the echocardiographically based PVS score.

\section{DISCUSSION}

Primary PVS is rare, accounting for only $0.4 \%$ to $0.6 \%$ of specimens reported from large registries and cardiovascular surgical series. ${ }^{7-9}$ The clinical presentation can vary from discrete stenosis at the venoatrial junction to diffusely narrow vessels, intraparenchymal stenosis, and vein atresia. $^{10-12}$ Other cardiac defects are often seen in association with PVS, including ventricular septal defects, atrial septal defects or patent ductus arteriosus, tricuspid atresia, Ebstein anomaly, tetralogy of Fallot, scimitar syndrome, cor triatriatum, and univentricular circulations. ${ }^{1,13}$

The clinical presentation varies according to the degree of involvement of the single veins and the number of veins affected. ${ }^{14}$ Although the severe stenosis of 1 vein or a low grade of stenosis in more than 1 vein may go undetected for years, ${ }^{15}$ severe stenosis of both veins unilaterally is normally clinically significant because of the consequent ventilation-perfusion mismatch in the involved lung. When severe disease involves the veins on both sides, the prognosis is poor and life expectancy rarely exceeds 12 months. ${ }^{16,17}$

Since the first reported repair by Kawashima and colleagues, ${ }^{18-20}$ a variety of surgical techniques, both percutaneous and surgical, have been adopted to relieve obstruction, with minimal success related to restenosis and poor survival associated with persistent pulmonary hypertension. The sutureless technique is designed to limit the degree of reactive postoperative intimal proliferation by avoiding contact with the vein wall. A few authors, however, including our group, have described a sutureless technique to repair PVS after repair of total anomalous pulmonary venous connection, showing improved survival and reduced need for reinterventions. ${ }^{4,6}$

Since 1998, all patients with a diagnosis of PVS (either primary or secondary) have undergone repair at our institution with the sutureless technique. The technique includes the initial complete resection of the stenotic portions and the incision of the veins retrogradely into their intraparenchymal portion. The atrial wall is then directly anastomosed to the pericardium, allowing the free egress of blood from the lungs into the left atrium.

This report presents our experience with this procedure applied to patients with primary PVS. Mortality was as high as $47 \%$ for the whole cohort and remained high at $42 \%$ even when we excluded those 4 patients who underwent the initial repair with nonsutureless techniques. We found that at least 1 postoperative reintervention was required in $22 \%$ of the patients, and multiple interventions were required in $10 \%$. The high overall mortality recorded

TABLE 3. Pulmonary vein stenosis scores stratified by outcome

\begin{tabular}{lccccccc}
\hline & Preoperative & At repair & $\mathbf{1 ~ m o}$ & $\mathbf{3 ~ m o}$ & $\mathbf{6}$ mo & 12 mo & At follow-up \\
\hline Survivors & $4.4 \pm 1.51$ & $1.6 \pm 2.05$ & $1.5 \pm 1.88$ & $1.8 \pm 1.89$ & $2.0 \pm 2.10$ & $2.2 \pm 2.83$ & $2.0 \pm 2.53$ \\
Nonsurvivors & $7 \pm 1.92$ & $3.5 \pm 3.45$ & $4.3 \pm 4.0$ & $5.4 \pm 3.35$ & $7.4 \pm 3.13$ & $6.5 \pm 6.36$ \\
$P$ value & .0015 & .1036 & .0714 & .0307 & .0147 & .5154 & - \\
\hline
\end{tabular}




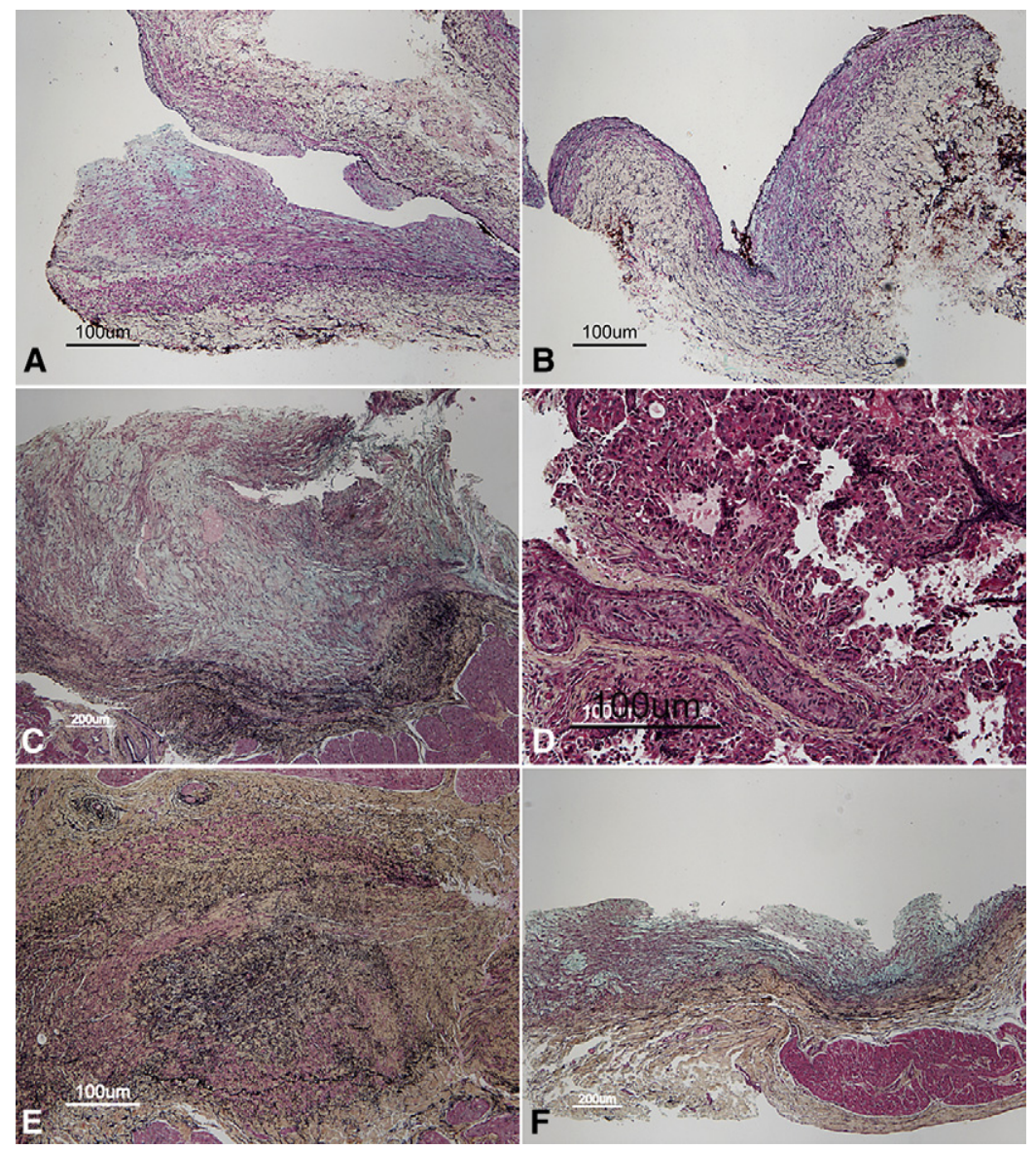

FIGURE 4. A and B, Vein biopsy specimens from patient at time of repair. There is severe obstruction caused by fibrointimal proliferation in A and nearly normal architecture in B. C and D, Patient with severe bilateral stenosis and suprasystemic pulmonary hypertension. Venoatrial junction shows marked neointimal proliferation (C), and lung biopsy specimen shows grade 3 hypertensive changes. E, Patient operated on at age 10 months for scimitar syndrome and left-side pulmonary vein stenosis with suprasystemic pulmonary pressure (total pulmonary vein stenosis score of 10). Section shows complete occlusion of vein by fibroelastic tissue and maintained vein architecture (elastica still seen). Abundance of collagen (yellow brown) and elastic fibers (black) indicates longevity of lesion. F, Patient with total pulmonary vein stenosis score of 8 and suprasystemic pulmonary pressures was operated on at 9 weeks. Left side venoatrial junction shows abundant ground substance (blue green) and myofibroblasts. Collagen and elastic fibers are sparse, indicating recent lesion (Movat pentachrome stain).

in our series is consistent with previous reports of other groups that have adopted the sutureless technique ${ }^{2}$ for primary PVS.

Our logistic regression analysis showed that need for recurrent interventions, univentricular circulation, the technique used for repair, and prematurity were not independent risk factors for death, which is in contrast to other reports ${ }^{1,21}$; however, our failure to identify these variables as risk factors may be a limitation of the relatively small size of this cohort. We did identify preoperative PVS score as an independent risk factor for mortality, and this is consistent with the initial report on use of the PVS score by Yun and associates. ${ }^{4}$ In this analysis, we were able to refine the prognostic value of the PVS score by identifying a threshold of greater than 4 as a strong predictor of mortality.

When we used the PVS score as a marker for the behavior of the disease, we observed that surgery was generally suc- cessful in relieving the stenosis in most patients, but those patients with high preoperative scores had an important trend toward severe early restenosis. It is troubling to note that survivors after 5 to 10 years still have a trend toward late restenosis. The clinical significance of this observation is still unexplored, but it may provide some insight into the biologic factors that mediate late restenosis among survivors.

Sadr and colleagues ${ }^{3}$ reviewed the histologic specimens from 10 patients with the diagnosis of primary congenital PVS. They found abnormal intimal spindle cell proliferation together with excessive production of loose matrix and hypothesized that the restenosis process is due to an inherent hyperproliferative process, rather than to inflammation, thrombosis, or fibrosis. They also identified the proliferating cell as a myofibroblast type cell. ${ }^{3}$ Our pathology specimens confirmed some of those findings. 
Yamaki's group ${ }^{22,23}$ has investigated the effects of PVS on the lung vasculature in clinical models. Their work suggests that the early presence of obstruction leads to hypoplasia of the pulmonary arteries, which show small diameters and medial thickening in the presence of significant hypertension. They also showed how these changes are potentially reversible if the obstruction is relieved. ${ }^{22,23}$ In our series, we could demonstrate only mild intimal proliferation in lung veins and mild hypertensive changes in the pulmonary arteries of patients with successful relief of the stenosis.

In subsequent animal studies, Endo and coworkers ${ }^{24}$ showed that even unilateral obstruction induces medial thickening in both lungs, possibly as a result of reciprocal regulatory mechanisms between the lungs. These observations could explain the poor clinical responses of some patients to surgical repair and the apparent progression of the disease even when the initial repair seems successful. In addition, it could explain the similar outcomes in patients with unilateral and bilateral obstruction in our series.

\section{Study Limitations}

This is among the largest series published on repair of primary PVS, with a long follow-up of 13 years. The sample size is still small, however, and this represents an important limitation of the study.

In this study we hypothesized that directing the analysis to the group of patients with the highest likelihood of restenosis (the primary PVS group) would increase the likelihood of detecting a benefit from the adoption of a sutureless technique. The overall poor survival does not support the hypothesis that the sutureless technique is a superior surgical strategy in patients with primary PVS.

Another important limitation of this study is that the PVS score relies on retrospective data derived primarily from echocardiography. Although intraoperative and pathologic findings seems to support the echocardiographic data, a thorough validation is necessary to its broader application, possibly with a more consistent correlation with angiography, magnetic resonance angiography, and computed tomographic scan.

\section{CONCLUSIONS}

Primary PVS remains associated with high mortality despite surgical repair. The use of the sutureless technique is not universally effective in avoiding restenosis and reduce fatal pulmonary hypertension, but in the subset of patients with low preoperative PVS scores it is associated with satisfactory survival and with a significant intraoperative decrease in the PVS score. Use of a preoperative score of greater than 4 as a predictor of mortality may provide useful prognostic information to guide decision making in clinical practice.

\section{References}

1. LaBourene JI, Coles JG, Johnson DJ, Mehra A, Keeley FW, Rabinovitch M. Alterations in elastin and collagen related to the mechanism of progressive pulmonary venous obstruction in a piglet model. A hemodynamic, ultrastructural, and biochemical study. Circ Res. 1990;66:438-56.

2. Devaney EJ, Chang AC, Ohye RG, Bove EL. Management of congenital and acquired pulmonary vein stenosis. Ann Thorac Surg. 2006;81:992-6.

3. Sadr IM, Tan PE, Kieran MW, Jenkins KJ. Mechanism of pulmonary vein stenosis in infants with normally connected veins. Am J Cardiol. 2000;86: 577-9, A10.

4. Yun TJ, Coles JG, Konstantinov IE, Al-Radi OO, Wald RM, Guerra V, et al. Conventional and sutureless techniques for management of the pulmonary veins: Evolution of indications from postrepair pulmonary vein stenosis to primary pulmonary vein anomalies. J Thorac Cardiovasc Surg. 2005;129:167-74.

5. Lacour-Gayet F, Zoghbi J, Serraf AE, Belli E, Piot D, Rey C, et al. Surgical management of progressive pulmonary venous obstruction after repair of total anomalous pulmonary venous connection. J Thorac Cardiovasc Surg. 1999; 117:679-87.

6. Najm HK, Caldarone CA, Smallhorn J, Coles JG. A sutureless technique for the relief of pulmonary vein stenosis with the use of in situ pericardium. J Thorac Cardiovasc Surg. 1998;115:468-70.

7. Samanek M, Voriskova M. Congenital heart disease among 815,569 children born between 1980 and 1990 and their 15-year survival: a prospective Bohemia survival study. Pediatric Cardiology. 1999;20:411-7.

8. Shone JD, Amplatz K, Anderson RC, Adams P Jr, Edwards JE. Congenital stenosis of individual pulmonary veins. Circulation. 1962;26:574-81.

9. van Son JA, Danielson GK, Puga FJ, Edwards WD, Driscoll DJ. Repair of congenital and acquired pulmonary vein stenosis. Ann Thorac Surg. 1995;60: 144-50.

10. Latson LA, Prieto LR. Congenital and acquired pulmonary vein stenosis. Circulation. 2007;115:103-8.

11. Herlong JR, Jaggers JJ, Ungerleider RM. Congenital Heart Surgery Nomenclature and Database Project: pulmonary venous anomalies. Ann Thorac Surg. 2000;69(4 Suppl):S56-69.

12. Neill CA. Development of the pulmonary veins; with reference to the embryology of anomalies of pulmonary venous return. Pediatrics. 1956;18:880-7.

13. Ito M, Kikuchi S, Hachiro $\mathrm{Y}$, Abe T. Congenital pulmonary vein stenosis associated with cor triatriatum. Ann Thorac Surg. 2001;71:722-3.

14. Holcomb RG, Tyson RW, Ivy DD, Abman SH, Kinsella JP. Congenital pulmonary venous stenosis presenting as persistent pulmonary hypertension of the newborn. Pediatr Pulmonol. 1999;28:301-6.

15. Tan CW, Munfakh N, Helmcke F, Abourahma A, Caspi J, Glancy DL. Congenital bilateral pulmonary venous stenosis in an adult: diagnosis by Echo-Doppler. Catheter Cardiovasc Interv. 2000;49:328-30.

16. Driscoll DJ, Hesslein PS, Mullins CE. Congenital stenosis of individual pulmonary veins: clinical spectrum and unsuccessful treatment by transvenous balloon dilation. Am J Cardiol. 1982;49:1767-72.

17. Sun CC, Doyle T, Ringel RE. Pulmonary vein stenosis. Hum Pathol. 1995;26: 880-6.

18. Kawashima Y, Ueda T, Naito Y, Morikawa E, Manabe H. Stenosis of pulmonary veins: Report of a patient corrected surgically. Ann Thorac Surg. 1971;12: 196-202.

19. Mendelsohn AM, Bove EL, Lupinetti FM, Crowley DC, Lloyd TR, Fedderly RT, et al. Intraoperative and percutaneous stenting of congenital pulmonary artery and vein stenosis. Circulation. 1993;88(5 Pt 2):II210-7.

20. Tomita H, Watanabe K, Yazaki S, Kimura K, Ono Y, Yagihara T, et al. Stent implantation and subsequent dilatation for pulmonary vein stenosis in pediatric patients: maximizing effectiveness. Circ J. 2003;67:187-90.

21. Drossner DM, Kim DW, Maher KO, Mahle WT. Pulmonary vein stenosis: prematurity and associated conditions. Pediatrics. 2008;122:e656-61.

22. Endo M, Yamaki S, Ohmi M, Tabayashi K. Pulmonary vascular changes induced by congenital obstruction of pulmonary venous return. Ann Thorac Surg. 2000; 69:193-7.

23. Maeda K, Yamaki S, Yokota M, Murakami A, Takamoto S. Hypoplasia of the small pulmonary arteries in total anomalous pulmonary venous connection with obstructed pulmonary venous drainage. J Thorac Cardiovasc Surg. 2004; 127:448-56.

24. Endo M, Yamaki S, Hata M, Saiki Y, Tabayashi K. Pulmonary vascular changes induced by unilateral pulmonary venous obstruction. Pediatr Cardiol. 2002;23: $420-5$. 